\title{
Clustering household energy-saving behaviours by behavioural attribute
}

Hilary S. Boudet ${ }^{\mathrm{a} *}$, June A. Flora ${ }^{\mathrm{b}}$ and K. Carrie Armel ${ }^{\mathrm{c}}$

a School of Public Policy / Sociology, Oregon State University, 300BGilkey Hall, Corvallis, Oregon 97301, USA, hilary.boudet@oregonstate.edu.

b Solutions Science Lab, School of Medicine, Stanford University.

${ }^{c}$ Precourt Energy Efficiency Center, Stanford University.

Keywords: conservation, pro-environmental behaviour, cluster analysis, residential energy

\begin{abstract}
Research on household energy conservation often categorizes targeted behaviours by their behavioural attributes (e.g., savings, cost, frequency). The most common distinction in the literature divides behaviours as follows: (1) low-impact, low-cost, repetitive behaviours that result in a loss of comfort or curtailment behaviours and (2) high-impact, high-cost, infrequent behaviours that result in no loss of amenities or efficiency behaviours. However, such categorizations have often been ad hoc and two-dimensional (e.g., low-impact vs. high-impact, low-cost vs. high-cost). In contrast, we systematically assess a large range of household energysaving behaviours $(\mathrm{N}=261)$ across nine attributes - energy savings, cost, frequency of performance, required skill level, observability, locus of decision, household function, home topography, and appliance topography. By clustering behaviours according to these attributes, we discern four clusters of energy-saving behaviours: family style, call an expert, household management and weekend project. We discuss the implications of these clusters for intervention design.
\end{abstract}




\section{Clustering household energy-saving behaviours by behavioural attribute}

\section{Introduction}

Changing energy use behaviour within the household has a great potential to both combat climate change and preserve environmental resources, especially if enacted collectively. In fact, Dietz et al. (2009) estimated that through targeting travel and residential energy use, carbon emissions could be decreased by $7.4 \%$ in the United States. Furthermore, programs targeting behaviour change can be implemented faster than other approaches that would require largescale policy or infrastructure changes and can thus stave off some of the adverse consequences of carbon emissions while such long-term solutions are put into place(Dietz et al., 2009). Household decisions - like whether to weatherize or hang dry clothes - play a large role in energy usage and associated carbon emissions. Put simply, "changing... behaviour is central to achieving a sustainable future" (McKenzie-Mohr, 2000, 544). Given the importance of this "behavioural wedge" in combatting climate change, understanding how households make decisions with regard to energy use and encouraging energy conservation has become an important topic of research (Lutzenhiser, 1993; Wilson and Dowlatabadi, 2007).

Household energy-saving behaviours are diverse, relating to lighting, cooking, heating/cooling, laundry, entertainment, hygiene, etc. (Leightyand Meier, 2011; Woods, 2008). Moreover, even within a subset of behaviours, such as those related to heating, recommended energy-saving actions like decreasing the thermostat setting or installing an energy-efficient heating system vary widely in terms of monetary cost, required skill and frequency of performance - and thus interventions aimed at changing these behaviours must also vary (Karlin et al., 2014; Urban and Scasny, 2014). However, using multiple intervention strategies to target individual behaviours, while addressing these differences,can create problems of information 
overload (Eppler and Mengis, 2004), single action bias (Weber, 2006), and a potential rebound effect (Berkhout et al., 2000). Another approach is to classifyenergy-saving behavioursinto groups based on shared combinations ofbehavioural attributes (e.g., savings, cost, frequency, etc.), allowing for one intervention to target multiple, similar behaviours (Karlin et al., 2014). We define behavioural attributes as the "constituent characteristics that comprise a behavioural domain" (Rimal et al., 2011, 18).

The most common classification of energy-saving behavioursused by scholars is between curtailment and efficiency(Abrahamse et al., 2005; Attari et al., 2010; Barr et al., 2005; Black et al., 1985; Dillman et al., 1983; Gardner and Stern, 2008; Karlin et al., 2014; Poortinga et al., 2003; Schultz, 2010; Steg, 2008; Strömberg et al., 2015; Urban and Scasny, 2014). Curtailment behaviours refer to "low cost (or free) energy-saving behaviours...that entail a cut back on amenities or comfort and must be repeated frequently to continue energy savings, [such as] turning off lights, unplugging appliances, or reducing appliance usage" (Karlin et al., 2014, 6). In contrast, efficiency behaviours refer to "infrequent structural changes and /or those requiring investments or purchases...but result in no loss of amenities with longer-lasting energy conservation effects... [such as] purchasing energy-efficient equipment or products or investing in structural or building envelope changes to the home" (Karlin et al., 2014, 6).

Such classifications, however, have often been ad hoc and two-dimensional, e.g., lowimpact vs. high-impact, low-cost vs. high-cost. Moreover, as lamented by Urban and Scasny(2014), "the literature does not give a clear answer to the question whether there are general classes of energy-saving behaviour and if so, how many they are, and what are the dimensions along which energy-saving behaviours can be classified" (2). In attempt to fill this gap, our analysis is the first of which we are aware that systematically assesses a large range of 
energy-saving behaviours ( $\mathrm{N}=261$ ) across severaltheoretically-derived attributes (energy savings, cost, frequency of performance, required skill level, observability, locus of decision, household function, home topography, and appliance topography). By clustering behaviours according to these attributes, we discern four clusters of energy-saving behaviours - family style, call an expert, household management and weekend project.

While still exploratory in nature, these behavioural clusters suggest more targeted intervention strategies than those associated with promoting energy conservation holistically (see, for example, Scheuthle et al., 2005) or the common curtailment / efficiency divide. At the same time, targeting clusters of lifestyle-related behaviours may lead to greater impact by encouraging the spread of behaviours from one household member to another orfrom one similar behaviour to another - the so-called "spill-over effect" (Whitmarsh and O'Neill, 2010). Identifying behavioural clusters for effective and efficient intervention is likely of particular interest to utilities interested in flexible energy demand to ensure grid reliability (Grueneich, 2015). Moreover, potential synergies exist with recent work identifying energy consumption lifestyles (or "load shapes") of customers based on data from advanced metering infrastructure (Kwac et al, 2015).

The article proceeds as follows. We first presentsome relevant theoretical perspectives on behavioural attributes from a range of disciplines. Then, we review existing behavioural classifications of energy-saving behaviours and the attributes they imply. Next,we provide information about our research methods, including how we developed our list of energy-saving behaviours, how we coded attributes and how we clustered behaviours. Finally, we devote the bulk of the article to a description of our behaviour clusters.Following Stern (2000), we adopt an impact-oriented definition of energy-saving behaviours - actions that reduce energy use. Thus, 
we focus on household energy-saving behaviours that directly reduce energy use, such as installing an energy-efficient appliance. We do not include actions that may indirectly influence energy use, such as installing an in-home monitoring device or communicating with household members about energy use.

\subsection{Literature review}

\subsubsection{Relevant theoretical perspectives on behavioural attributes}

Economic, psychological and sociological theories related to energy-saving behaviour identify potentially relevant behavioural attributes. In line with a more rational, economic view of decision making, energy savings and cost associated with a particular behavioural changeare important attributes. With energy seen as a commodity and household residents as consumers, much of the research on energy consumption has been dominated by theories of rational choice(Stern and Aronson, 1984). As rational decision makers, energy users should behave no differently than other consumers - the only behaviour attributes that matter are cost and savings.

Even within this economic perspective and building on work in psychology, particularly applied behaviour analysis (Cooper et al., 2007), researchers have defined the attribute of cost broadly to include non-monetary costs like time and effort - thus incorporating concerns about the frequency and ease of performing certain behaviours (Diekmann and Preisendorfer, 2003). Such work has highlighted the role of cost and associated behavioural attributes (e.g., frequency, cognitive skill, difficulty, etc.) - in combination with values, attitudes and norms - in determining behaviour. For example, Stern and Aronson (1984) argue that "psychological variables such as attitudes and personal norms appear to have more effect on relatively inexpensive, easy-to-perform energy-saving actions" (285). This link has been formalized in the aptly-named low-cost hypothesis, which argues that "the strength of the effects of environmental 
concern on environmental behaviour diminishes with increasing behavioural costs" (Diekmann and Preisendorfer, 2003, 441). Indeed, in their analysis of survey responses about behavioural performance of eight energy-saving behaviours, Karlin et al. (2014) found that environmental concern and motivation influenced curtailment behaviours more than efficiency behaviours, providing empirical support for the application of the low-cost hypothesis to energy-saving behaviour.

At the same time, the frequency of the performance of an energy-saving behaviour is also important from the perspective of habit formation - an outlook that is decidedly at odds with rational choice theory and draws largely on learnings from social-psychology. According to this line of reasoning, frequent behaviours performed in stable contexts often develop into habits, which in turn become strong predictors of behaviour, in spite of or even in outright contradiction to an individual's environmental concern or economic incentives (Maréchal, 2009). Thus, habits become "a context-dependent form of acquired automaticity" (Maréchal, 2009, 1696). To encourage habitual energy-saving behaviours, successful interventions may need to be timed to coincide with changing circumstances - such as relocation or the birth of a child (Maréchal, 2009).

Expanding beyond these more common behavioural attributes (and moving further into the realm of social-psychology), other researchers have highlighted learnings from theories about the diffusion of innovations (Brown, 1984; Costanzo et al., 1986; Wilson and Dowlatabadi, 2007). This literature shows that five perceived attributes of an innovation explain most of the variation in its adoption rates - (1) relative advantage over what it replaces; (2) compatibilitywith the needs and experience of the adopter;(3) complexityin terms of perceived difficulty;(4) trialability, or the degree to which it can be tested at a small-scale before full 
adoption; and (5) observability, or its visibility to others(Rogers, 2003). Specifically, these attributes of an innovation influence attitude formation, particularly through the establishment of social norms(Wilson and Dowlatabadi, 2007).

As researchers attempt to understand household as opposed to individual conservation behaviour, family lifestyles (routines, patterns, schedules) and concerns about comfort become important (Gladhart and Roosa, 1982). Behavioural choices that “...from an energy conservation perspective are unexpected, hard to interpret, or irrational, usually make sense in the context of everyday family life" (Weihl and Gladhart, 1990, 178). Who is the decider - or the locus of decision - in terms of the adoption of a particular behaviour change also becomes critical(Gladhart and Roosa, 1982; Grønhøj, 2006; Grønhøj and Thøgersen, 2012). Particularly, with the increasing interest in youth-centred approaches to encourage familial energy conservation (Boudet et al., 2014; Fell and Chiu, 2014; Flora et al., 2014), knowing who can access certain behaviours can help researchers better select target behaviours. For example, a child can encourage a parent to fill the dishwasher completely before running but does not likely have the knowledge, skill or parental permission to perform this behaviour independently.A teenager,in contrast, is likely rewarded by a parent for completing dishwashing tasks.

Sociologists in particular have sought to infuse the study of energy conservation with its relationship to societal routines, norms and practices - shifting the focus away from individual behavioural choices to the demand for energy services (e.g., comfort, cleanliness, convenience, etc.) or its end uses (Shove, 2003; Shove and Walker, 2014). Such work has highlighted the "embeddedness" of energy use in daily routines like cooking, cleaning, child care and mobility (Wilson and Dowlatabadi, 2007). In some ways, these ideas echo the concept of behaviour function - or the effect the behaviour produces in the environment - from applied behaviour 
analysis in psychology, suggesting that the function a particular behaviour serves is an important attribute (Cooper et al., 2007).

Ecological models of behaviour - which have become increasingly used in health research - emphasize the context within which behaviour takes place, while still incorporating social and psychological factors (Stokols, 1992). A focus on the context within which household energy-saving behaviour takes place, aspects of the physical environment surrounding a behaviour - e.g., where in the home the behaviour takes place and what type of appliance or device is used to accomplish the behaviour - then become important attributes in designing interventions (Guin and Kirby, 2013).

\subsubsection{Existing behavioural classifications and implied attributes}

Previous research has often classified energy-saving behaviours in some way(Diekmann and Preisendorfer, 2003; Dietz et al., 2009; Fujimi et al., 2015; Karlin et al., 2014; Leighty and Meier, 2011; Poortinga et al., 2003; Strömberg et al., 2015; Urban and Scasny, 2014)- although not using a theoretically-derived, attributed-based approach. ${ }^{1}$ In what is perhaps the most thorough review of the literature on householdenergy-saving behavioural classifications, Karlin et al.(2014)identified two primary classifications: curtailment andefficiency. As summarized in Urban and Scasny(2014), the distinction between curtailment versus efficiency behaviours impliesnine attributes:"high frequency versus low frequency, low cost versus high cost, behavioural versus structural $^{2}$ measure, reversible versus permanent measure, loss of comfort versus no lifestyle changes, little cognitive effort versus substantial cognitive effort, lower versus higher impact in terms of energy savings, available to anybody versus access to the measure

\footnotetext{
${ }^{1}$ We provide a more comprehensive review of existing behavioural classifications in our online supplement, which we summarize here.

${ }^{2}$ Structural here refers to a change that impacts that structure of the dwelling, for example, installing an energyefficient appliance (an efficiency behaviour), as opposed to a change to behavioural routines, for example, turning out lights when not in use (a curtailment behaviour).
} 
restricted by income and/or home ownership, and moral versus rational ${ }^{3}$ motivation" (3).Karlin et al. (2014)also identified another classification in the literature apart from curtailment and efficiency called management or maintenance that includes behaviours like setting the thermostat back each night or maintaining energy-efficient appliances. These management behaviours lead to greater savings than typical curtailment behaviours but require similar changing of behavioural patterns and ongoing maintenance of the changed behaviour (Kempton et al., 1992; Ölander and Thøgersen, 1995; Van Raaij and Verhallen, 1983; Dietz et al., 2009).

Behavioural classifications also appear in more practical guides aimed at utilities interested in encouraging energy conservation. For example, Ignelzi et al. (2013)classified behaviours according to several attributesidentified in the literature - end use, purchase versus no-purchase, no/low-cost versus major cost, energy or dollar savings potential, frequency or popularity of actions, and difficulty or complexity - and identified seven groupsof energy-related behaviours - change your habits, get rid of stuff, maintain your home, use your equipment better, upgrade your home, automate your home, and invest in your home. In another example, Manning (2009)classifies direct sustainable behaviours into five groups: making a one-time purchase, making a frequent purchase, curtailing or ending a certain type of behaviour, substituting a new for an old behaviour, and making a behaviour more efficient.

Beyond the curtailment / efficiency divide, the literature provides no clear answer as to what distinct classifications of behaviours exist or what constellation of behavioural attributes is most important in distinguishing energy-saving behaviours (Urban and Scasny, 2014).

\footnotetext{
${ }^{3}$ Rational here refers to a change that, because of its large monetary costs and energy savings, will likely involve a calculation of costs and benefits (an efficiency behaviour), as opposed to a change that may not result in large energy savings but requires strong moral commitment to maintain (a curtailment behaviour).
} 


\subsection{Limitations of current approaches and the importance of an attribute-centred approach to behaviour}

Our examination of the literature revealed several limitations. First, most studies examine only a limited set of energy-saving behaviours - never more than 40 - in many ways limited by the predominant methodological choice of surveying and thus the number of behaviours about which a researcher can reasonably ask. Yet, qualitative research that asks participants openended questions about energy-saving behaviours undertaken reveals many more potential actions - for example, Woods (2008) identified 100 different energy-saving behaviours. Another limitation is that many of the behavioural classifications used (e.g., curtailment versus efficiency) were conceptual in nature and not necessarily based on either theory or empirical examination. Moreover, the behavioural attributes on which classifications were based (e.g., energy savings, cost, frequency) were implied, rather than explicit. And, when categories within an attribute (e.g., high cost vs. low/no cost) were discussed, they were almost always twodimensional. It is worth noting that this is one likely reason that the maintenance category has often gone overlooked. While most measures of behavioural attributes range along continuums (e.g., frequency of performance can range from multiple times a day to daily to weekly to monthly to seasonally to annually), the curtailment / efficiency categorization scheme forces a false dichotomization (e.g., low vs high frequency). Many management behaviours actually fall somewhere in between these dichotomies and thus defy categorization as either a curtailment or efficiency behaviour.

We aim to combat these limitations by: (1) coding energy-saving behaviours according to theoretically-derived attributes and (2) conducting an empirical analysis of the attributes to determine theoretically and empirically derived classifications or clusters of energy-saving 
behaviours. Our attribute-centred approach models multiple behaviours into clusters that share the same underlying properties - with the ultimate goal of allowing interventions to generate changes in clusters of behaviours (Rimal et al., 2011). Such an approach has been gaining traction in public health research, as exemplified by Rimal et al.'s (2011)call for a return to the "building blocks" of behaviours in "an attribute-centred approach to understanding health behaviour" (16). Such a strategy will be most useful in combination with the other more dominant approaches to research on pro-environmental behaviour - examining interactions "between attributes and characteristics of people, between attributes and social or environmental contexts" (Rimal et al., 2011, 31). It also avoids the pitfalls discussed above associated with targeting individual behaviours one at a time, while providing for a more nuanced understanding for effective intervention than targeting energy conservation holistically or dividing behaviours by the dominant curtailment / efficiency categorization.

\section{Methodology and data}

Content analysis and categorization were used to derive clusters of behaviour. Content analysis is a technique for compressing large amounts of data through coding it according to a set of specified attributes. We identified, collected, and coded data on 261 energy-saving behaviours between April 2010 and June 2013. Each behaviour was coded according to a set of nine attributes derived with reference to both theory and previous literature(energy savings, cost, frequency of performance, required skill level, observability, locus of decision, household function, home topography, and appliance topography). Correlation analysis was performed to explore relationships among the six attributes whose ratings were ordinaland to confirm that our coding procedures resulted in logical interrelationships among attributes. We then clustered behaviours according to the ordinal attributes identified, such that the resulting clusters were 
theoretically relevant, empirically derived, and both mutually exclusive and mutually exhaustive. The following four sections (data collection, criteria for inclusion and exclusion, coding and analysis) describe the methods used in this study in greater detail.

\subsection{Data collection}

To develop a list of direct energy-saving behaviours, we drew from public and commercial lists, particularly the U.S. Department of Energy's (2012)Energy Savers Guide, the California Energy Commission's “Flex Your Power” website(Efficiency Partnership, 2012), and a comprehensive list published by the city of Townsville, Australia (Townsville City Council, 2012). Over 500 behaviours were initially identified from these lists. Our strategies for refining this initial list are outlined below.

With the exception of two attributes - energy savings and cost, attributes could be coded without the use of external data sources. To code cost, we relied on internet searches of various home improvement, department and technology store websites (e.g., Home Depot, Sears, Best Buy) to price behaviours that required purchasing.To code energy savings, we relied on public databases when available (Wenzel et al., 1997; U.S. Energy Information Administration, 2009). For the remaining behaviours, we collaborated with engineering students and used home tests, internet research, and frameworks with building stock and appliance use assumptions to calculate energy savings. Our online supplement provides information about our data sources and assumptions for energy savings calculations by behaviour.

\subsection{Criteria for inclusion and exclusion}

Of the initial list of 500 behaviours, we first eliminated redundant behaviours, including those that were exactly the same or those that were the inverse of another action (e.g.,wash laundry in cold water and stop using hot water to wash laundry). In all cases, we selected 
positive actions (e.g., wash laundry in cold water) over negative actions (e.g., stop using hot water to wash laundry). We then removed behaviours related to new home construction andeliminated behaviours that seemed unlikely to be adopted by the general population due to significant barriers related to current standards of comfort, cleanliness and convenience (Shove, 2003). Such excluded behaviours included watching less television, wearing clothes longer prior to washing, and taking a bucket bath.Finally, we systematized levels of behavioural choice within the list, particularly related to replacing incandescent bulbs with more energy-efficient lighting choices to increase the specificity of the action for coding purposes. These changes resulted in a list of 320 behaviours. An additional 19\% were dropped because we were unable to determine associated energy savings, resulting in a final list of 261 behaviours (see online supplement for the full list). All behaviours were restated in a consistent manner; starting with an action verb and ending with the target outcome of the behaviour as the direct object (e.g., install an "Energy Star" refrigerator). Our resultant list included 60 action verbs with install being the most frequently used verb at $32 \%$ of behaviours. The next most frequent verbs were turn off (17\%), set (16\%), insulate (14\%), and clean $(12 \%)$.

\subsection{Coding}

To identify attributes for coding, we started with the theories outlined above (economic theory, applied behaviour analysis, diffusion of innovation, family lifestyle, and social ecology). We then refined our list of relevant attributes based on the literature specific to energy-saving behaviour reviewed above, resulting in nine theoretically-derived behavioural attributes: energy savings, cost, frequency of performance, required skill level, observability, locus of decision, household function, home topography, and appliance topography. 
The coding scheme for each attribute's categories was developed inductively and iteratively. Two team members developed initial operational definitions of each attribute and a coding scheme for its attribute categories. Two other members then independently coded the behaviours intothe proposed attribute categories. Coder training included lengthy review of the operational definition of the attribute, its categories, an examination of up to twenty behaviours, and discussion of problematic areas. If the two independent coders agreed on $80 \%$ or more of the codings of an attribute's categories when coding all 261 behaviours, then the remaining mismatched ratings were adjusted via discussion of the entire research team. If the independent coders' agreement was under $80 \%$, then the definitions and attribute categories were reexamined and refined, and the coding process was repeated until $80 \%$ agreement was achieved.

Table 1 presents the theoretical perspectives, attributes, categories, and category frequencies within our list of behaviours (see our online supplement for how we coded each behaviour and our codebook). We discuss each attribute in turn below.

[Insert Table 1 about here]

We coded each of the behaviours into one of five categories according to their energy savings impact in kilowatt-hours per year $(\mathrm{kWh} / \mathrm{yr})$. We coded based on ranges of energy savings (as opposed to specific kilowatt-hours/year saved) because savings often vary by building, appliance, geographic area and implementation factors. Almost half of the behaviours (46\%) were coded as saving more than $750 \mathrm{kWh} / \mathrm{yr}$. About $20 \%$ of the behaviours were coded as resulting in marginal energy savings of 1 to 25 kilowatt hours per year $(\mathrm{kWh} / \mathrm{yr})$. The remainder o fell into the categories in between - 15\% saved $25-100 \mathrm{kWh} / \mathrm{yr}, 12 \%$ saved $101-250 \mathrm{kWh} / \mathrm{yr}$, and $10 \%$ saved $250-750 \mathrm{kWh} / \mathrm{yr}$. 
We also coded each of the behaviours into one of five categories related to the fiscal cost of performing the behaviour. Our internet searches for purchase costs yielded a range of prices and allowed coders to place an action within one of the five categories based on the median price. More than half of the behaviours were coded as costing no more than $\$ 20-43 \%$ under $\$ 5$ and $11 \% \$ 5$ to $\$ 20$. About $20 \%$ of the behaviours were coded as costing between $\$ 100$ and $\$ 1,000$, and $11 \%$ as more than $\$ 1,000$.

Frequency of performance referred to the occurrence rate of the behaviour and was coded over six categories ranging from infrequent to very high frequency. Many behaviours (38\%) on the list were coded as being performed infrequently (i.e., only once every three or more years). These included such behaviours as major appliance purchases and home weatherization. Another $15 \%$ of behaviours were coded as occurring annually (i.e., every one to three years), such as small appliance purchases and appliance maintenance. We coded the second largest set of behaviours (20\%) as occurring with very high frequency (multiple times a day), such as turning off lights and unplugging/turning off computers and entertainment devices.

Required skill level refers to the amount of ability an adult would have to have to adopt a behaviour and was coded over four categories, ranging from no to high skill. We did not, however, take into account the amount of time the person needs to dedicate to perform the behaviour or the information required to decide whether to perform the behaviour. We coded $52 \%$ of behaviours as requiring low or no skill. According to our coding scheme, no skill behaviours do not require reading instructions (e.g., closing shades or drapes to keep heat in or out, turning off lights, or installing a CFL), while low skill behaviours may require glancing at instructions (e.g., installing a low flow shower head). We coded $21 \%$ as requiring medium skills - reading instructions and/or having tools (e.g., purchasing a new refrigerator or wrapping the 
hot water heater). Another $28 \%$ of behaviours were coded as demanding significant skill such that an expert may be needed to perform the behaviour, e.g., installing insulation or high efficiency windows.

Observability is defined as the degree to which the features and benefits of a behaviour are visible, noticeable and understandable to others - i.e., the ease with which the members and guests of a household can notice the adoption of an energy-saving behaviour. We coded over a third of the behaviours (34\%) as highly observable, both by household members and by outsiders and household members. Just under a third of the behaviours (31\%) were coded as observable by household members only. Interestingly, $35 \%$ of behaviours were coded as invisible even to household members and observable only by the person who performs the behaviour. Such invisible behaviours include, for example, adjusting the hot water heater temperature.

Locus of decisions divides behaviours according to the person that usually makes the decision to perform a behaviour. The coding is not based on who can perform the task (which is captured in required skill level) but who makes the decision to adopt a behaviour. For example, a teenager can install a CFL but is unlikely to make the decision to replace an existing bulb with a $\mathrm{CFL}$ - a choice which lies with an adult in the household. For behaviours that involve a change in the way a task is performed (less frequently, more slowly, etc.), the behaviour is coded based on the locus of decision for the change. We assumed that the decision to perform the initial task had already been taken (for example, a teenager who has already decided to cook can make the decision whether s/he is going to use a metal or ceramic pan). For tasks that cannot be performed by certain groups, the coding excludes these groups from any behaviours that include these tasks (e.g., a child cannot iron and thus will never make a decision about which garments should be ironed first). We also assumed that teenagers and children do not have purchasing power. 
However, when the purchase of an item has already been decided within the family, they can contribute to the final choice of it or the choice among items in the same price range (e.g., they can select the colour of their room but cannot make the decision to replace light bulbs). In terms of locus of decision, we coded over three-quarters of behaviours (78\%) requiring an adult to decide whether to adopt the behaviour, such as large purchases or household organization and maintenance. Our coders decided teens could perform 13\% (e.g., unplugging the charger once a phone is charged) and young children $9 \%$ of the behaviours (e.g., turning off lights).

Household function refers to the energy service the behaviour provides -- e.g., thermal comfort, lighting, nourishment, etc. - and is divided into seven categories. When the energysaving behaviour involved an appliance's maintenance and not its use, we coded it as housekeeping (e.g., cleaning refrigerator coils regularly was coded as housekeeping not food/nourishment). We coded $38 \%$ of the behaviours on our list as increasing thermal comfort. These behaviours involved space heating and cooling, from installing "Energy Star" air conditioners to changing thermostat settings. Another $19 \%$ of behaviours were coded as serving a housekeeping function (e.g., cleaning and maintenance). The smallest coded categories were behaviours associated with hygiene (i.e., taking shorter showering) (8\%) and outdoor recreation (e.g., covering heated swimming pools with solar blankets) (2\%).

Home topography refers to the location where an energy-saving behaviour takes place in the home. We coded each behaviour with respect to the most likely spatial location in or outside the home. The most commonly coded location for behaviours was the shell (or building envelope) of the house: $35 \%$ of the behaviours were coded as involving its walls, floors, ceiling, or roof. The second most commonly coded locations for behaviours were kitchen/dining areas 
$(16 \%)$, multiple areas (e.g., behaviours associated with lighting fixtures) (15\%), and storage spaces (e.g., behaviours associated with the hot water heater) (14\%).

Appliance topography classifies behaviours in terms of their relationship to the ecology or "landscape" of appliances - in the home: large, small, craft and recreational, electronics and computers, lighting and non-electrical. Interestingly, this coding scheme also most closely mimics categorizations in stores or online for purchasing energy-efficient equipment. Most behaviours were coded as involving large electric appliances (33\%) or no electrical devices (36\%). The remainder of the behaviours involves small electrical appliances (10\%), electronics (10\%), lighting (9\%), and craft and recreation (2\%).

\subsection{Analysis}

To analyse our data, we first used Spearman correlation coefficients to explore relationships among the six attributes whose ratings were ordinal: energy savings, cost, frequency of occurrence, required skill level, observability and locus of decision. K-means cluster analysis was then performed using standardized measures of five of these ordinal attributes to group behaviours. Energy savings was not included in the K-means clustering, so that it could serve as a hold-out variable against which to examine the clusters.

Cluster analysis classifies cases into smaller, more homogeneous groups based on patterns of responses across variables or scales(Hair and Black, 2000). Bivariate analyses then compared energy savings and our three nominal attribute attributes(household function, home topography and appliance topography) among the behaviour clusters. Effect sizes are reported where appropriate. Effect size statistics indicate the strength of relationships between independent and dependent variables, are standardized estimates of the magnitude of these 
variable relationships, and are influenced less by sample size than tests for statistical significance (Cohen, 1988). SPSS 21.0 and SAS 9.4 software were used for these analyses.

\section{Results and discussion}

\subsection{Intercorrelations among attributes}

Table 2 presents the intercorrelations among attributes with ordinal categories. Frequent behaviours require fewer skills $(r=-.78 ; p<.001)$, cost less $(r=-.72 ; p<.001)$, and are more likely to have a locus of decision that involves teens or children $(r=.62 ; p<.001)$ than behaviours that occur less often.

[Insert Table 2 about here]

Required skill level is highly positively correlated with cost $(r=.71 ; p<.001)$ and negatively correlated with locus of decision $(r=-.54 ; p<.001)$. In other words, the more skill a behaviour requires, the more likely it is to be expensive and performed by adults.

Observability is positively and significantly correlated with locus of decision $(r=.31$; $p<.001)$ and frequency $(r=.20 ; p=.004)$ but negatively correlated with required skill level $(r=$ $-0.21 ; p<.001)$. Thus, behaviours that are frequent, less demanding in terms of skill, and/or performed by the whole household are more observable.

Locus of decision is negatively correlated with cost $(r=-.49 ; p<.001)$. Thus, behaviours that the whole household, including children and teens, can perform cost less than behaviours that only adults can perform.

Energy savings is negatively correlated with both frequency $(r=-.28 ; p<.001)$ and locus of decision $(r=-0.23 ; p<.001)$. In other words, frequent and kid-friendly behaviours tend to save less energy. On the other hand, energy savings are positively correlated with skill and cost $(r=.25 ; p<.001$ and $r=.37 ; p<.001$, respectively) 


\subsection{Behaviour clusters}

A series of two- to six-group cluster analyses showed that a four-group solution provided the best fit for the data, and groups were labelled: (1) family style, (2) call an expert, (3) household management, and (4) weekend project. These groups were compared in terms of their coding classifications in the original five behavioural attributes used for the cluster analysis (see Table 3). Behaviours in the family style cluster had the highest mean scores on frequency of performance and locus of decision (indicating that children can decide to perform these behaviours) and the lowest mean scores on cost and required skill level. Behaviours in the call an expert cluster had the highest mean scores on cost and required skill level and the lowest mean scores on frequency, observability and locus of decision (indicating that adults decide to perform these behaviours). Behaviours in the weekend project cluster had the highest mean scores on observability. Behaviours in the household management cluster had neither the highest nor lowest mean scores on any of the attributes. In terms of cost, frequency, skill and locus of decision, the mean scores of behaviours in the household management and weekend project clusters fell somewhere in between those of the family style and call an expert clusters, though mean scores of the household management behaviours indicate that these behaviours are less costly, more frequent, and less demanding in terms of skills required as compared to those in the weekend project cluster. For both the household management and weekend project clusters, mean locus of decision scores indicated that adults generally decide to perform these behaviours. The largest percentage of behaviours was classified in the household management group ( $n=84$. $32 \%)$, followed by the call an expert group $(n=69,26 \%)$, weekend project group $(n=58,22 \%)$, and finally the family style group $(n=50,19 \%)$.

[Insert Table 3 about here] 
Two analyses confirmed the stability of this cluster solution. First, data were randomly sorted and cluster analyses were conducted after each of three random sorts. These analyses supported the solution identifying four groups of energy-saving behaviours. Second, discriminant analysis was conducted to determine how well the five behavioural attributes predicted the four cluster groups. All variables significantly predicted the clusters, Wilks' lambda $U=.183$ to .512 , $F=81.72$ to $381.78, p<.001$. These variables correctly classified $100 \%$ of family style behaviours, $93 \%$ of call an expert behaviours, $94 \%$ of household management behaviours, and $98 \%$ of weekend project behaviours. Overall, $96 \%$ of behaviours were correctly classified by this discriminant analysis. These additional analyses supported the solution identifying four distinct groups of behaviours.

\subsection{Relationships between behaviour clusters and other attributes}

Relationships between our behaviour groupings and energy savings are shown in Figure 1. The family style cluster contains both the largest proportion of behaviours that result in the least energy savings ( $38 \%$ of behaviours save 1 to $25 \mathrm{kWh} / \mathrm{yr}$ ) and a significant proportion of high energy-saving behaviours (36\%). Both the household management and weekend project clusters have many behaviours in the mid-ranges of savings ( $48 \%$ and $43 \%$ of behaviours saving 26-750 kWh/yr, respectively). The call an expert cluster contains the largest percentages of behaviours that save over $750 \mathrm{kWh} / \mathrm{yr}(68 \%)$. A Kruskal-Wallis test was conducted to evaluate differences between behaviours in the four clusters in terms of energy savings. The test, which was corrected for tied ranks, was significant $\chi^{2}(3, \mathrm{~N}=261)=19.5, p<.001$. Specifically, the call an expert cluster includes behaviours with the highest potential for energy savings when compared to those in both the family style cluster (Mann-Whitney $U=1053.0, Z=-3.98, p$ 
$<.001, r=-.37$ ) and the household management cluster (Mann-Whitney $U=2032.0, Z=-3.415$, $p=.001, r=-.28)$.

[Insert Figure 1: Energy behavior clusters by energy savings in $\mathrm{kWh} / \mathrm{yr}$ ]

Relationships between our behaviour groupings and household function are shown in Figure 2. Many of the behaviours in the call an expert cluster (58\%) serve a thermal comfort function in the household. A majority of the behaviours in the family style cluster serve either thermal comfort (26\%) or food/nourishment (30\%) functions. Nearly half of the behaviours in the household management cluster (43\%) serve a housekeeping function. Many of the behaviours in the weekend project cluster serve a thermal comfort (40\%), entertainment / computing / communication (21\%), or lighting (19\%) function. A Monte Carlo estimate of the Fisher's exact test was conducted to evaluate the relationship between behaviours in the four clusters in terms of household function. The relationship between our behaviour groupings and household function was statistically significant, $p<.0001$.

[Insert Figure 2: Energy behaviour clusters by household function] Relationships between our behaviour groupings and home topography are shown in Figure 3. Many energy-saving behaviours in the call an expert and weekend project clusters occur in the shell of the home (59\% and $40 \%$, respectively). However, these clusters differ in their next-most-common locations - for call an expert, $20 \%$ of behaviours occur in storage space (i.e., basements, closets and water heater storage sites) while for weekend project, $14 \%$ of behaviours occur in multiple locations throughout the home. No single category of home topography makes up a majority of the other clusters. Many of the behaviours in the family style cluster occur in three locations: kitchen/dining (30\%), the shell (16\%), and multiple locations (14\%). In the household management cluster, many behaviours occur in the shell (24\%), multiple 
locations (24\%), or storage spaces (21\%). A Monte Carlo estimate of the Fisher's exact test was conducted to evaluate the relationship between behaviours in the four clusters in terms of home topography. The relationship between our behaviour groupings and home topography was statistically significant, $p<.0001$.

[Insert Figure 3: Energy behaviour clusters by home topography]

Relationships between our behaviour groupings and appliance topography are shown in Figure 4. No category of this attribute makes up a majority of any of the behaviour clusters. Instead, across all five clusters, two categories are most prominent — behaviours involving large electrical/gas appliances (making up $21 \%$ to $43 \%$ of the clusters) and behaviours involving nonelectrical devices and actions ( $26 \%$ to $43 \%$ of the clusters). What distinguishes the four clusters in terms of the appliance topography of their behaviours is the relative size of these two categories and the percentage of the cluster made up of other categories of behaviours. For example, a large majority (81\%) of the call an expert cluster is behaviours in the large appliance and the non-electrical categories, and the next largest categories are behaviours involving small electrical/gas appliances (7\%) and electronics / computing (7\%). The family style cluster follows the same general pattern, but fewer of its behaviours $(62 \%)$ are in the large appliance and the non-electrical categories while a larger percentage of its behaviours involve small appliances (18\%). Additional analysis (not shown in Figure 4) of the non-electrical behaviours in these clusters revealed another difference: Non-electrical behaviours requiring expert skill (like weatherization) are located in the call an expert cluster, while low-skill non-electrical behaviours (like closing drapes to keep heat in or out) are in the family style cluster. The cluster with the largest percentage of behaviours involving large appliances is household management (43\%). Next largest categories in household management are behaviours involving non-electrical 
devices (26\%) and lighting (15\%). Weekend project behaviours are more likely to involve nonelectrical devices (41\%) and electronics / computers (19\%). A Monte Carlo estimate of the Fisher's exact test was conducted to evaluate the relationship between behaviours in the four clusters in terms of appliance topography. The relationship between our behaviour groupings and appliance topography was statistically significant, $p<.0001$.

[Insert Figure 4: Energy behaviour clusters by appliance topography]

\section{Conclusions and policy implications}

Our coding and clustering of 261 energy-saving behaviours across nine different behavioural attributes produced four distinct clustersof energy-saving behaviour: (1) family style, (2) call an expert, (3) household management and (4) weekend project. We provide a brief summary of each of these clusters, as well as their relationships to previous attempts to cluster behaviours by attribute in the literature.

The family style cluster (19\% of behaviours) includes frequent, low cost behaviours that require little or no skill, can be performed and observed by all members of the household, but

yield low energy savings. Most behavioursin the family style are related to thermal comfort and eating. Not surprisingly, these behaviours take place inmultiple locations throughout the home but are most concentrated in the kitchen or dining area. In many ways, this cluster most aligns with the curtailment classification of energy-saving behaviour mentioned in previous literature. It includes such behaviours as turning off lighting, appliances and devices when not in use; air drying laundry and dishes; setting the thermostat lower in winter and higher in summer; and closing refrigerator doors promptly.

In contrast, the call an expert cluster ( $26 \%$ of behaviours) includes infrequent, costly behaviours that require a high level of skill, are less easily observed by others, but yield high 
energy savings. Thermal comfort is their primary household function, and they are mainly associated with large electrical/gas appliances. Wall, attic and window insulation, as well as other major weatherization efforts and energy-efficient appliance installationsthat require family budgeting and are beyond the reach of household expertise characterize this cluster. It most resembles the efficiency classification of energy-saving behaviour mentioned in previous literature.

The household management cluster is the largest cluster (32\% of behaviours) and is typified by housekeeping and home organization behaviours with a medium frequency (monthly or seasonally), low cost, and low skill requirements. Most of these behaviours are observable to other family members but not necessarily outside guests and take place in the shell of the home, storage spaces or multiple locations. This cluster is characterized by behaviours mostly conducted by adults with large electrical/gas appliances. The energy savings of individual behaviours within this cluster are relatively low. In many ways, this cluster most resembles the management or maintenance classificationof energy-saving behaviour mentioned in previous literature. It includes behaviours that do not easily fit into either the curtailment or efficiency categories, like cleaning and replacing filters around the home; installing energy-efficient lighting; programming thermostats; and setting appropriate temperatures for refrigerators, freezers and hot water heaters.

Finally, the weekend project cluster ( $22 \%$ of behaviours) is comprised of relatively infrequent, medium cost, medium-to-high skill and highly observable behaviours, such as painting; installing energy-efficient electronics and appliances; hanging curtains; and installing awnings. These are the types of behaviours a family might take on as a weekend project resulting in energy savings second-only to the call an expert cluster. Like the call an expert 
cluster, these behaviours often occur in the shell but are more likely to involve non-electrical devices or computers. This cluster does not appear to be well-represented in the previous literature.

\subsection{Policy implications}

The four behaviour clusters identified here offer multiple implications for planners of household energy conservation programs and are likely of particular interest to utilities seeking more flexibility in energy demand to ensure grid reliability (Grueneich, 2015). In terms of audience selection and targeting, for example, behaviours in the family style and household management clusters might be most appropriate for families with young children who do not have the financial resources to purchase energy-saving appliances. Behaviours in these two clusters may also be better suited for renters than those in the call an expert or weekend project clusters because renters are less likely than homeowners to make energy-saving investments. The point here is that behaviour clusters can guide program planners in strategically selecting audiences for particular messages.

Focusing on behavioural clusters may also allow policy makers and administrators to better design program messages. For example, behaviours in the family style cluster might be best encouraged via contextualized messages related to family discussions, family energy-use plans, and family engagement in energy monitoring via websites and online applications. Behaviours in the call an expert cluster, in contrast,are likely not conducive to the involvement of the entire family. Instead, messaging might be more effective when it is framed around adult decision-making related to budgets and investments. Effective messaging for the weekend project cluster likely lies somewhere in between since such actions are visible to the entire family and may actually encourage teaching between parents and children. 
Program strategies might also be rendered more effective by clustering energy-saving behaviours by attribute. For example, high-frequency, low-cost behaviours, like those in the family style cluster, likely require interventions that cue, monitor, support and reward habit development. Such interventions may be most effective when seeking to influence children, since family style behaviours are frequent, visible, and easily emulated. In contrast, one-time, high-cost behaviours, like those in the call an expert cluster, should likely involve different strategies, focusing on planning, scheduling and contractor vetting. For seasonal behaviours, like those in the call and expert and weekend project clusters, checklists and "how to" messages might be the most effective strategies.

Grueneich and Jacot (2014) argue that three forces - significant investments in advanced metering infrastructure, state policies, and private sector innovation - are creating a "paradigm shift" in "demand-side" efficiency, ushering in "the analytics age of efficiency" (78). We believe there areimportant potential synergies between our approach of clustering energy-saving behaviours by theoretically-derived attributes and efficiency analytics. With utilities increasingly considering the role of behaviour, our behaviour clusters inform, among other things, the timing of interventions - for example, targeting household management behaviours during spring cleaning and the audience - for example, targeting whole families instead of individual bill payers around family style behaviours. Our work also has implications for demand response programs. For example, if peak hours of energy use and thus demand reduction occur during dinner hours, our coding of attributes related to household function, household topography and appliance topography could help identify relevant target behaviours for intervention. 


\subsection{Limitations and suggestions for future research}

Our approach is necessarily limited to the behaviours included in our list, the attributes we examined and how we defined those attributes. Future studies could expand the set of behaviours clustered to contain, for example, indirect household energy-saving behaviours or energy-saving behaviours related to transportation decisions. Additional behavioural attributes could be examined - for example, trialability (i.e., the degree to which a behaviour may be experimented with on a limited basis) (Rogers, 2003)or a behaviour's relationship to traditional gender roles (Carlsson-Kanyama and Lindén, 2007). We also did not incorporate a measure of the length and complexity of the cognitive-behaviour chain that precedes an energy-saving action (Kazdin, 2009). However, one could speculate that family style behaviourshave short and simple chains, while weekend projectbehaviours have lengthier and more complex chains. Future studies should explicitly consider chains of preceding behaviours (such as budgeting and researching), which may prove critical to understanding impediments to behaviour adoption and maintenance.

Perhaps the most promising direction for future research, however, is to connect these four behavioural clusters to individual characteristics, public perceptions, and social and environmental contexts. The decision to engage in energy-saving behaviour is not entirely shaped by personal, social or cultural factors. Instead, it is determined, at least to some extent, by how individuals, households and communities respond to the energy-saving options that are presented to them. The cost, the required skills, the frequency with which the activity is performed, the "fit" of behaviour in household routines, and the amount of energy that is likely to be saved are all critical factors in determining whether an energy-saving behaviour is likely to be embraced and sustained. Stated differently and perhaps more starkly, the responses of 
individual, households and communities to efforts to change their energy-saving behaviour may depend more on the nature of the behaviours themselves than on their social standing and values. However, this remains an empirical question that future work should address.

In the long term, neither distinct demographic characteristics, individual values and beliefs, household context, nor behavioural attributes are likely, in and of themselves, sufficient to understand and promote energy-saving behaviour. Rather, we would argue that it is the interaction of these factors that should guide energy policies, programs and interventions. It is the investigation of this interaction that we hope to explore in future work and would encourage others to do so as well.

\section{$5 \quad$ Acknowledgements}

This research was supported in part by the Department of Energy ARPA-E (DEAR0000018), California Energy Commission (PIR-10-054), and Precourt Energy Efficiency Center. The views and opinions of the authors expressed herein do not necessarily state or reflect those of the United States Government or any agency thereof. The authors would also like to thank SahilBhagat, Marilyn Cornelius, Emily Humphreys, Mark Needham, Larson Plano, Maria Roumpani, ShimaSalehi and Dave Voelker for their assistance in coding and data analysis.

\section{References}

Abrahamse, W., Steg, L., Vlek, C., Rothengatter, T., 2005. A review of intervention studies aimed at household energy conservation. J. Environ. Psychol. 25, 273-291.

Barr, S., Gilg, A.W., Ford, N., 2005. The household energy gap: examining the divide between habitual- and purchase-related conservation behaviours. Energy Policy 33, 1425-1444.

Berkhout, P.H.G., Muskens, J.C., Velthuijsen, J.W., 2000. Defining the rebound effect. Energy Policy 28, 425-432.

Black, J.S., Stern, P.C., Elworth, J.T., 1985. Personal and contextual influences on household energy adaptations. J. Appl. Psychol. 70, 3-21.

Boudet, H., Ardoin, N.M., Flora, J., Armel, K.C., Desai, M., Robinson, T.N., 2014. Energy behaviours of northern California Girl Scouts and their families. Energy Policy 73, 439-449. Brown, M.A., 1984. Change mechanisms in the diffusion of residential energy conservation practices: an empirical study. Technol. Forecast. Soc. Chang. 25, 123-138. 
Carlsson-Kanyama, A., Lindén, A.-L., 2007. Energy efficiency in residences: challenges for women and men in the North. Energy Policy 35, 2163-2172.

Cohen, J., 1988. Statistical Power Analysis for the Behavioral Sciences, 2nd ed. Lawrence

Erlbaum, Hillsdale.

Cooper, J.O., Heron, T.E., Heward, W.L., 2007. Applied Behavior Analysis, 2nd ed. Pearson, New York.

Costanzo, M., Archer, D., Aronson, E., Pettigrew, T., 1986. Energy conservation behavior: the difficult path from information to action. Am. Psychol. 41, 521-528.

Diekmann, A., Preisendorfer, P., 2003. Green and greenback: the behavioural effects of environmental attitudes in low-cost and high-cost situations. Ration. Soc. 15, 441-472.

Dietz, T., Gardner, G.T., Gilligan, J., Stern, P.C., Vandenbergh, M.P., 2009. Household actions can provide a behavioral wedge to rapidly reduce US carbon emissions. Proc. Natl. Acad. Sci. $106,18452-18456$.

Dillman, D.A., Rosa, E.A., Dillman, J.J., 1983. Lifestyle and home energy conservation in the United States: the poor accept lifestlye cutbacks while the wealthy invest in conservation. J.

Econ. Psych. 3, 299-315.

Efficiency Partnership, 2012. Flex your power.http://www.fypower.org/, last accessed 23 August 2012.

Eppler, M.J., Mengis, J. 2004. The concept of information overload: a review of literature from organization science, accounting, marketing, MIS, and related disciplines, Inf. Soc. 20, 325-344. Fell, M.J., Chiu, L.F., 2014. Children, parents and home energy use: exploring motivations and limits to energy demand reduction. Energy Policy 65, 351-358.

Flora, J., Saphir, M., Lappé, M., Roser-Renouf, C., Maibach, E., Leiserowitz, A., 2014.

Evaluation of a national high school entertainment education program: the alliance for climate education. Clim. Chang. 127, 419-434.

Gardner, G.T., Stern, P.C., 2008. The short list: the most effective actions U.S. households can take to curb climate change. Environ. 50, 12-23.

Gladhart, P.M., Roosa, M.W., 1982. Family lifestyle and energy consumption: an energy adaptation model. J. Consum. Stud. Home Econ. 6, 205-222.

Grueneich, D.M., 2015. The next level of energy efficiency: the five challenges ahead. Electr. J. 28, 44-56.

Grueneich. D.M., Jacot, P.E., 2014. Scale, speed, and persistence in an analytics age of efficiency: how deep data meets big savings to deliver comprehensive efficiency. Electr. J. 27, 77-86.

Grønhøj, A., 2006. Communication about consumption: a family process perspective on 'green' consumer practices. J Consum. Behav. 5, 491-503.

Grønhøj, A., Thøgersen, J., 2012. Action speaks louder than words: the effect of personal attitudes and family norms on adolescents' pro-environmental behaviour. J. Econ. Psych. 33, 292-302.

Guin, A.H., Kirby, S.D., 2013. Exploring determinants of consumer energy conservation decision-making as a foundation for residential energy conservation programs. Forum Fam. Consum. Issues 18 .

Hair, J.F., Black, W.C., 2000. Cluster analysis, in: Grimm, L.G., Yarnold, P.R. (Eds.), Reading and understanding more multivariate statistics. American Psychological Association, Washington, DC. 
Ignelzi, P., Peters, J., Randazzo, K., Dougherty, A., Dethman, L., Lutzenhiser, L., 2013. Paving the way for a richer mix of residential behavior programs. California Investor-Owned Utilities, San Francisco, CA.

Karlin, B., Davis, N., Sanguinetti, A., Gamble, K., Kirkby, D., Stokols, D., 2014. Dimensions of conservation: exploring differences among energy behaviors. Environ. Behav. 46, 423-452.

Kazdin, A.E., 2009. Psychological science's contributions to a sustainable environment: extending our reach to a grand challenge of society. Am. Psychol. 64, 339-356.

Kempton, W., Darley, J.M., Stern, P.C., 1992. Psychological research for the new energy problems: strategies and opportunities. Am. Psychol. 47, 1213-1223.

Lutzenhiser, L., 1993. Social and behavioural aspects of energy use. Ann. Rev. Energy Environ. 18, 247-289.

Kwac, J., Flora, J., Rajagopal, R., 2014. Household energy consumption segmentation using hourly data. IEEE Trans. Smart Grid 5, 420-430.

Leighty, W., Meier, A., 2011. Accelerated electricityconservationinJuneau,Alaska: a

studyofhouseholdactivitiesthatreduceddemand25\%. Energy Policy 39, 2299-2309.

Manning, C., 2009. The psychology of sustainable behavior: tips for empowering people to take environmentally positive action. Minnesota Pollution Control Agency.

Maréchal, K., 2009. The crucial role of habits in energy consumption: an evolutionary approach on changing current patterns, Act! Innovate! Deliver! Reducing energy demand sustainably. European Council for an Energy Efficient Economy.

McKenzie-Mohr, D., 2000. Promoting sustainable behavior: an introduction to community-based social marketing. J. Soc. Issues 56, 543-554.

Ölander, F., Thøgersen, J., 1995. Understanding of consumer behaviour as a prerequisite for environmental protection. J. Cons. Pol. 18, 345-385.

Poortinga, W., Steg, L., Vlek, C., Wiersma, G., 2003. Household preferences for energy-saving measures: a conjoint analysis. J. Econ. Psych. 24, 49-64.

Rimal, R.N., Lapinski, M.K., Turner, M.M., Smith, K.C., 2011. The attribute-centered approach for understanding health behaviors: initial ideas and future research directions. Stud. Commun.

Sci. 11, 15-34.

Rogers, E.M., 2003. Diffusion of Innovations, 5th ed. Free Press, New York.

Sallis, J.F., Owen, N., Fisher, E.B., 2008. Ecological models of health behavior, in: Glanz, K., Rimer, B.K., Viswanath, K. (Eds.), Health Behavior and Education: Theory, Research and Practice. Jossey-Bass, San Francisco, CA, pp. 465-485.

Scheuthle, H., Carabias-Hütter, V., Kaiser, F.G., 2005. The motivational and instantaneous behavior effects of contexts: steps toward a theory of goal-directed behavior. J. Appl. Soc.

Psychol. 35, 2076-2093.

Schultz, P.W., 2010. Making energy conservation the norm, in: Ehrardt-Martinez, K., Laitner, J.A. (Eds.), People-centered initiatives for increasing energy savings. ACEEE, Washington, DC, pp. 251-262.

Shove, E., 2003. Converging conventions of comfort, cleanliness and convenience. J. Cons. Pol. 26, 395-418.

Shove, E., Walker, G., 2014. What is energy for? Social practice and energy demand. Theory Cult. Soc. 31, 41-58.

Steg, L., 2008. Promoting household energy conservation. Energy Policy 36, 4449-4453.

Stern, P.C., 2000. Toward a coherent theory of environmentally significant behavior. J Soc Issues 56, 407-424. 
Stern, P.C., Aronson, E. (Eds.), 1984. Energy Use: The Human Dimension. W.H.Freeman and Company, New York.

Stokols, D., 1992. Establishing and maintaining healthy environments: toward a social ecology of health promotion. Am. Psychol. 47, 6-22.

Strömberg, H., Selvefors, A., Renström, S., 2015. Mapping out the design opportunities: pathways of sustainable behaviour. Int. J. Sustain. Eng. 8, 163-172.

Townsville City Council, 2012. Townsville city council resident information.http://www.townsville.qld.gov.au/Pages/default.aspx, last accessed 23 Aug 2012. U. S. Department of Energy, 2012. Energy savers guide.http://energy.gov/energysaver/downloads/energy-saver-guide, last accessed 8 September 2015.

U.S. Energy Information Administration, 2009. Residential energy consumption survey. http://www.eia.gov/consumption/residential/data/2009/, last accessed 10 February 2016. Urban, J., Scasny, M., 2014. Structure of domestic energy saving: how many dimensions? Environ. Behav. 1-28.

Van Raaij, W.F., Verhallen, T.M.M., 1983. A behavioral model of residential energy use. J. Econ. Psych. 3, 39-63.

Weber, E.U., 2006. Experience-based and description-based perceptions of long-term risk: Why global warming does not scare us (yet). Clim. Chang. 77, 103-120.

Weihl, J. S., Gladhart, P. M., 1990. Occupant behavior and successful energy conservation: findings and implications of behavioral monitoring. Proceedings of the 1990 ACEEE summer study on energy efficiency in buildings, 2, 171-180.

Wenzel, T., P., Koomey, J., G., Rosenquist, G., J., Sanchez, M., C., Hanford, J., W., 1997. Energy Data Sourcebook for the U.S. Residential Sector. Lawrence Berkeley National Laboratory, Berkeley, CA.

Whitmarsh, L., O’Neill, S., 2010. Green identity, green living? The role of pro-environmental self-identity in determining consistency across diverse pro-environmental behaviours. J Environ. Psychol. 30, 305-314.

Wilson, C., Dowlatabadi, H., 2007. Models of decision making and residential energy use. Ann. Rev. Environ. Resour. 32, 169-203.

Woods, J., 2008. What people do when they say they are conserving electricity. Energy Politcy $36,1945-1956$. 
Table 1: Behavioural attributes, coding categories and frequencies

\begin{tabular}{|c|c|c|c|c|}
\hline $\begin{array}{l}\text { Theoretical } \\
\text { perspective }\end{array}$ & Attribute & Categories & Frequency & Percent \\
\hline \multirow{10}{*}{$\begin{array}{l}\text { Economic } \\
\text { theory }\end{array}$} & \multirow{5}{*}{ Energy savings } & 1 to $25 \mathrm{kWh} / \mathrm{yr}$ & 46 & 18 \\
\hline & & 25 to $100 \mathrm{kWh} / \mathrm{yr}$ & 38 & 15 \\
\hline & & 101 to $250 \mathrm{kWh} / \mathrm{yr}$ & 31 & 12 \\
\hline & & 251 to $750 \mathrm{kWh} / \mathrm{yr}$ & 25 & 10 \\
\hline & & Over $751 \mathrm{kWh} / \mathrm{yr}$ & 121 & 46 \\
\hline & \multirow{5}{*}{ Cost } & Under $\$ 5$ & 113 & 43 \\
\hline & & $\$ 5.01$ to $\$ 20$ & 28 & 11 \\
\hline & & $\$ 20.01$ to $\$ 100$ & 38 & 15 \\
\hline & & $\$ 100.01$ to $\$ 1000$ & 52 & 20 \\
\hline & & Over $\$ 1000$ & 30 & 11 \\
\hline \multirow{10}{*}{$\begin{array}{l}\text { Applied } \\
\text { behaviour } \\
\text { analysis }\end{array}$} & \multirow{6}{*}{$\begin{array}{l}\text { Frequency of } \\
\text { occurrence }\end{array}$} & Infrequent (once every 3 or more years) & 98 & 38 \\
\hline & & Annual (once every 1 to 3 years) & 39 & 15 \\
\hline & & Periodic, irregular low (seasonal) & 11 & 4 \\
\hline & & Regular, medium (monthly) & 29 & 11 \\
\hline & & Frequent (weekly) & 32 & 12 \\
\hline & & $\begin{array}{l}\text { Very frequent (daily or multiple times a } \\
\text { day) }\end{array}$ & 52 & 20 \\
\hline & \multirow{4}{*}{$\begin{array}{l}\text { Required skill } \\
\text { level }\end{array}$} & No skill & 89 & 34 \\
\hline & & Low skill & 46 & 18 \\
\hline & & Medium skill & 54 & 21 \\
\hline & & High skill & 72 & 28 \\
\hline \multirow{3}{*}{$\begin{array}{l}\text { Diffusion } \\
\text { of } \\
\text { innovation }\end{array}$} & \multirow{3}{*}{ Observability } & $\begin{array}{l}\text { Observable only by person performing } \\
\text { behaviour }\end{array}$ & 88 & 34 \\
\hline & & Observable only by household adults & 81 & 31 \\
\hline & & $\begin{array}{l}\text { Observable to guests, household } \\
\text { members, children }\end{array}$ & 92 & 35 \\
\hline \multirow{10}{*}{$\begin{array}{l}\text { Family } \\
\text { lifestyle }\end{array}$} & \multirow{3}{*}{$\begin{array}{l}\text { Locus of } \\
\text { decision }\end{array}$} & Adults only & 204 & 78 \\
\hline & & Adults and teens & 33 & 13 \\
\hline & & Adults, teens and children & 24 & 9 \\
\hline & \multirow{7}{*}{$\begin{array}{l}\text { Household } \\
\text { Function }\end{array}$} & Thermal comfort & 98 & 38 \\
\hline & & Food/nourishment & 32 & 12 \\
\hline & & Hygiene & 21 & 8 \\
\hline & & Lighting & 27 & 10 \\
\hline & & Housekeeping & 50 & 19 \\
\hline & & Outdoor recreation & 6 & 2 \\
\hline & & $\begin{array}{l}\text { Entertainment, computing and } \\
\text { communication }\end{array}$ & 27 & 10 \\
\hline
\end{tabular}




\begin{tabular}{lllll}
\hline $\begin{array}{l}\text { Theoretical } \\
\text { perspective }\end{array}$ & Attribute & Categories & Frequency & Percent \\
\hline $\begin{array}{l}\text { Social } \\
\text { ecology }\end{array}$ & & Shell & 92 & 35 \\
& & Kitchen/dining & 42 & 16 \\
& & Office & 9 & 3 \\
& Home & Entertainment space & 15 & 6 \\
& topography & Bedroom & 3 & 1 \\
& & Storage spaces & 37 & 14 \\
& & Oultiple locations & 38 & 15 \\
& & Butside of home & 19 & 7 \\
& & Large electrical appliance & 6 & 2 \\
\cline { 3 - 5 } & & Small electrical & 87 & 33 \\
& & Craft and recreational & 26 & 10 \\
& Appliance & Electronics and computers & 4 & 2 \\
& topography & Lighting & 27 & 10 \\
& & Non-electrical & 23 & 9 \\
& & & 94 & 36 \\
\hline
\end{tabular}

Table 2: Intercorrelations among behavioural attributes

\begin{tabular}{|c|c|c|c|c|c|c|}
\hline & $\begin{array}{l}\text { Energy } \\
\text { savings }\end{array}$ & Cost & Frequency & Skill & Observability & $\begin{array}{c}\text { Locus } \\
\text { of } \\
\text { decision }\end{array}$ \\
\hline Energy savings & - & & & & & \\
\hline Cost & $.37^{* *}$ & - & & & & \\
\hline Frequency & $-.28^{* *}$ & $-.72^{* *}$ & - & & & \\
\hline Skill & $.25^{* *}$ & $.71^{* *}$ & $-.78^{* *}$ & - & & \\
\hline Observability & -.07 & -.11 & $.20^{* *}$ & $-.21^{* *}$ & - & \\
\hline Locus of decision & $-.23^{* *}$ & $-.49^{* *}$ & $.62^{* *}$ & $-.54^{* *}$ & $.31^{* *}$ & - \\
\hline
\end{tabular}


Table 3: Comparisons of energy-saving behaviour clusters by clustering attributes

\begin{tabular}{lcccccc}
\hline & $n$ & Cost $^{\mathrm{a}}$ & Frequency $^{\mathrm{b}}$ & Skill $^{\mathrm{c}}$ & Observability $^{\mathrm{d}}$ & Locus of decision $^{\mathrm{e}}$ \\
Cluster & & $M$ & $M$ & $M$ & $M$ & $M$ \\
\hline Family style & 50 & 3.3 & 5.7 & 1.2 & 2.6 & $(S D)$ \\
& & $(2.7)$ & $(0.66)$ & $(0.37)$ & $(0.60)$ & 2.5 \\
Call an & 69 & 674.7 & 1.3 & 3.8 & 1.3 & $(0.50)$ \\
expert & & $(443.8)$ & $(0.70)$ & $(0.46)$ & $(0.46)$ & 1.0 \\
Household & \multirow{2}{*}{84} & 19.3 & 4.1 & 1.6 & 1.7 & $(0.00)$ \\
management & & $(62.1)$ & $(1.5)$ & $(0.76)$ & $(0.68)$ & 1.1 \\
Weekend & 58 & 330.5 & 1.4 & 3.1 & 2.8 & $(0.26)$ \\
project & & $(364.7)$ & $(0.60)$ & $(0.78)$ & $(0.40)$ & 1.0 \\
\hline
\end{tabular}

Cost categories range from $1=$ under $\$ 5$ to $5=$ over $\$ 1,000$. For ease of interpretation, the cost variable is presented as a grouped mean across all behaviors in the cluster using the midpoints of these original ranges $(\$ 2.50 ; \$ 12.50 ; \$ 60.00 ; \$ 550$; and $\$ 1200)$.

b Frequency categories range from $1=$ low to $6=$ high.

c Skill categories range from $1=$ low to $4=$ high.

d Observability categories range from $1=$ low to $3=$ high.

e Locus of decision categories range from $1=$ "adults only" to $3=$ "adults, teens, and children". 


\section{Figure 1}

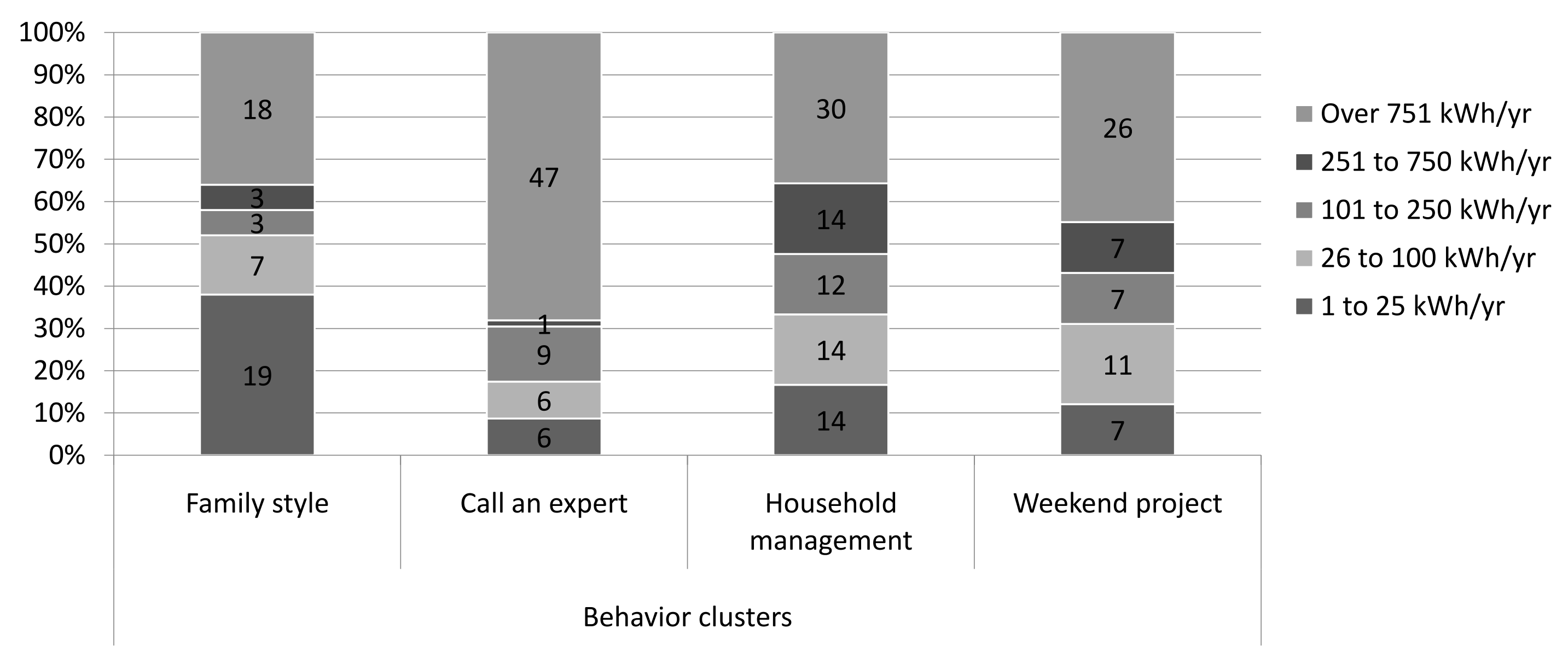




\section{Figure 1 (online)}

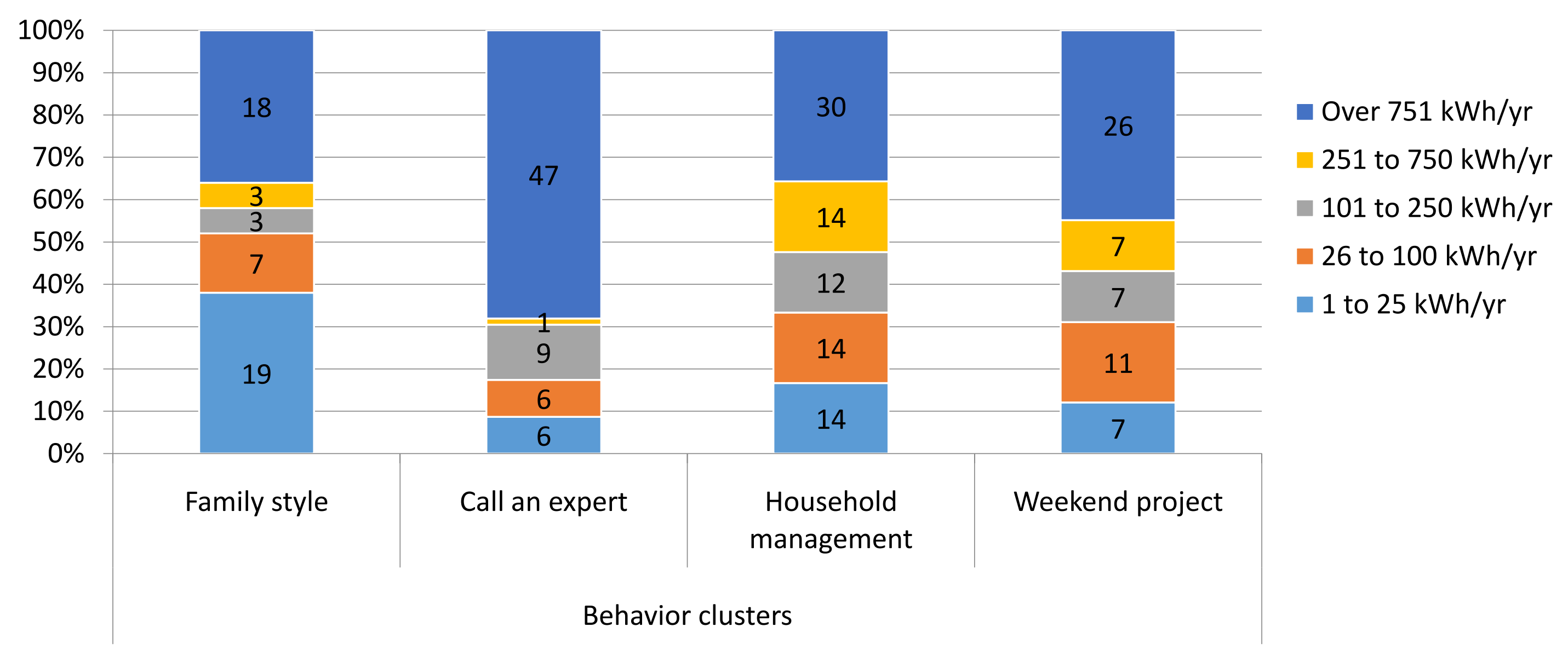




\section{Figure 2}

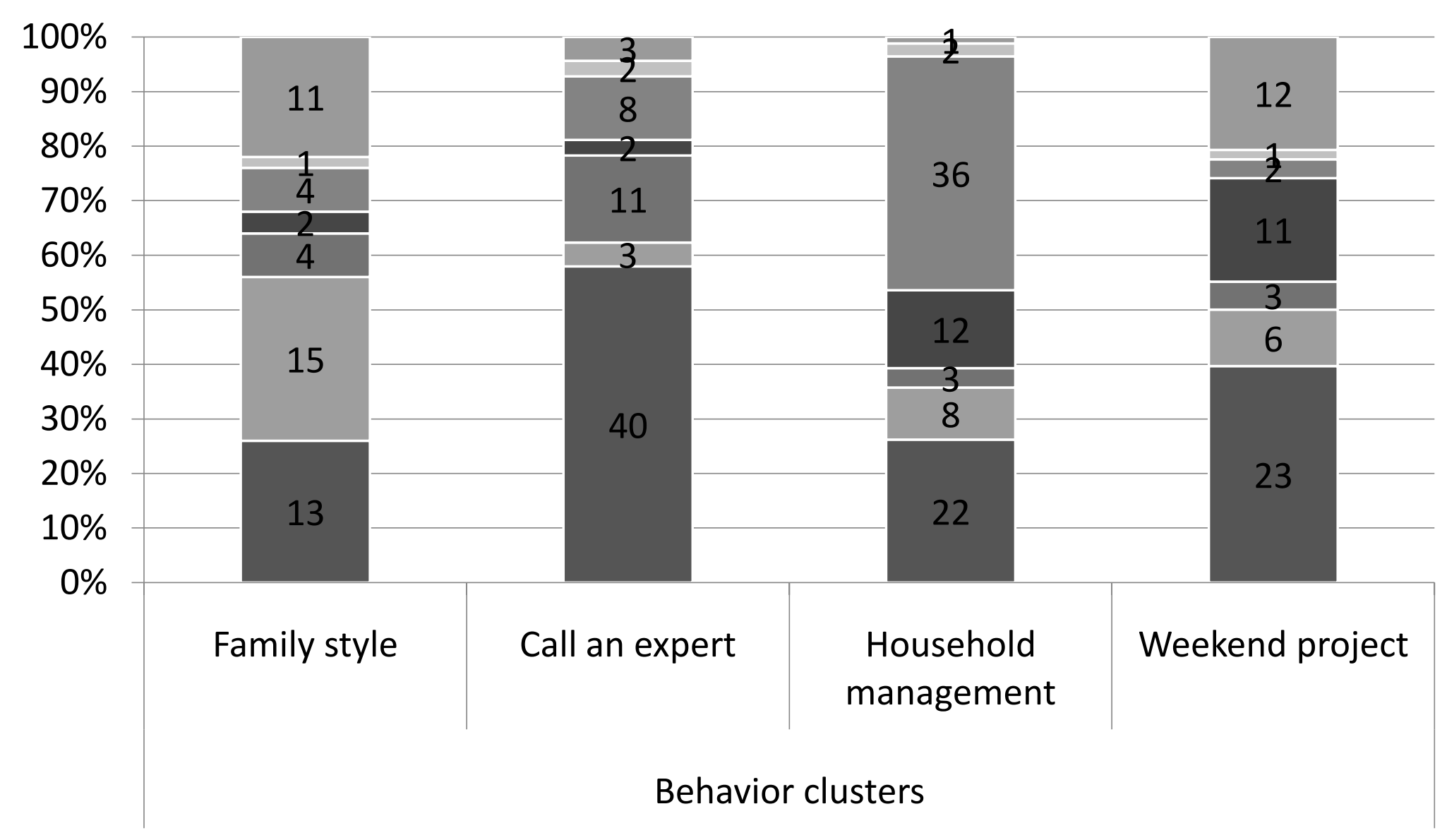

\section{Entertainment, computing and communication \\ - Outdoor recreation}

- Housekeeping

- Lighting

- Hygiene

Food/nourishment

- Thermal comfort 


\section{Figure 2 (online)}

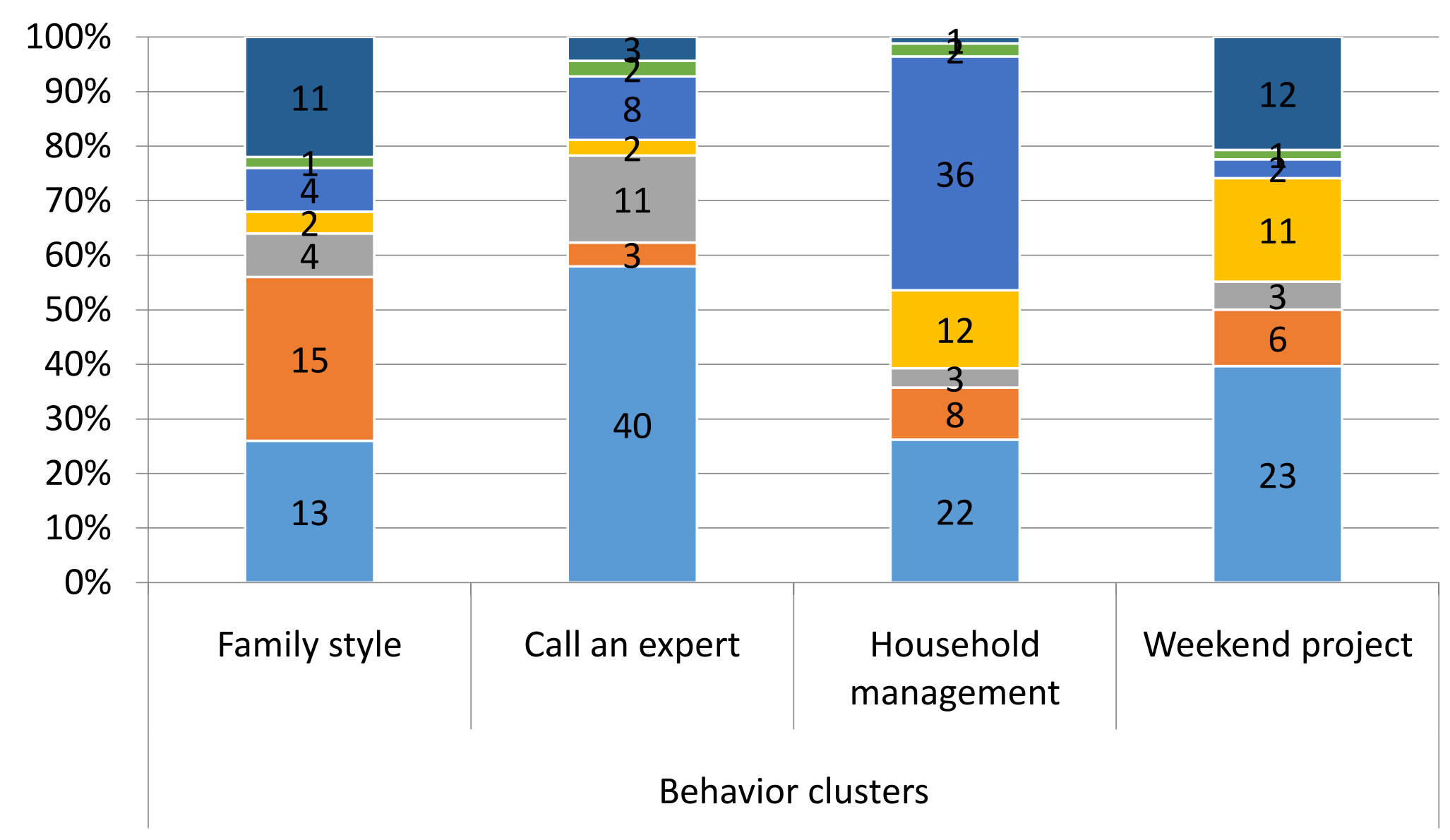

- Entertainment, computing and communication

- Outdoor recreation

- Housekeeping

Lighting

Hygiene

Food/nourishment

- Thermal comfort 


\section{Figure 3}

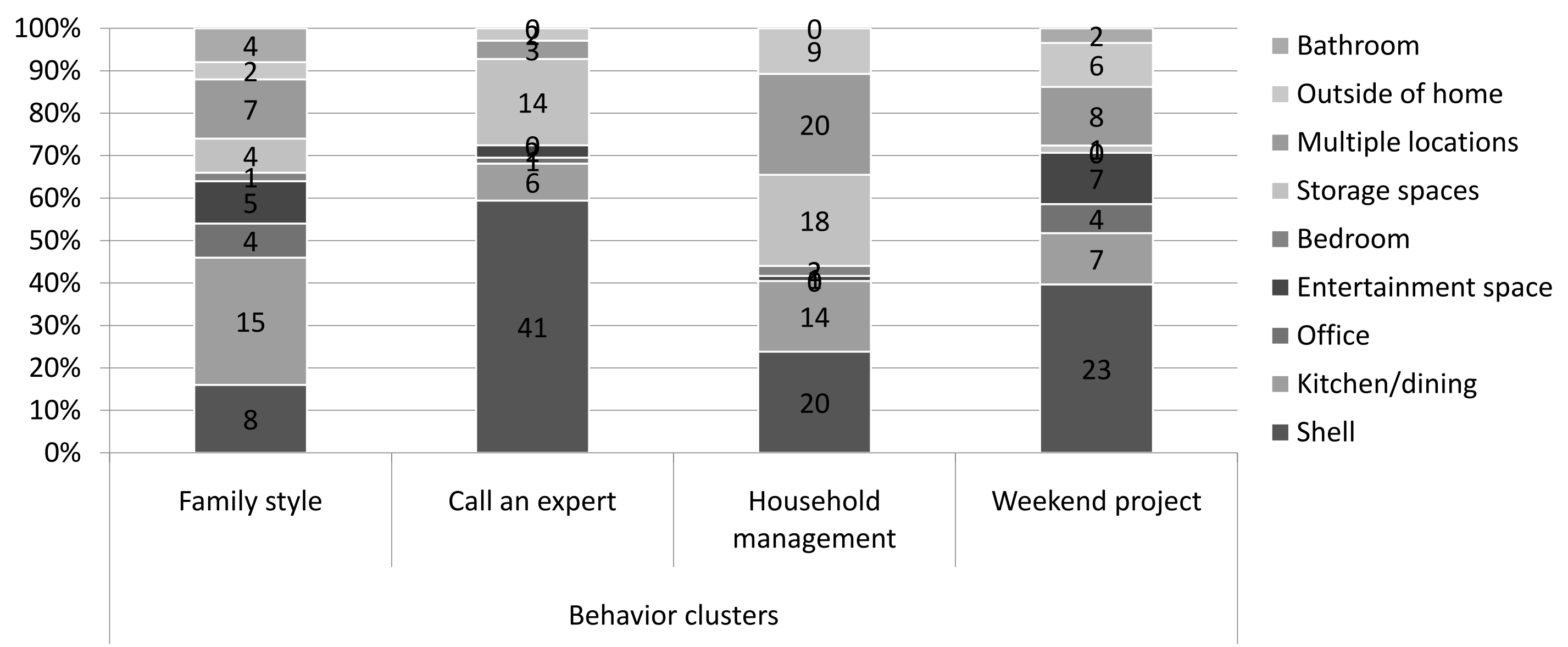




\section{Figure 3 (online)}

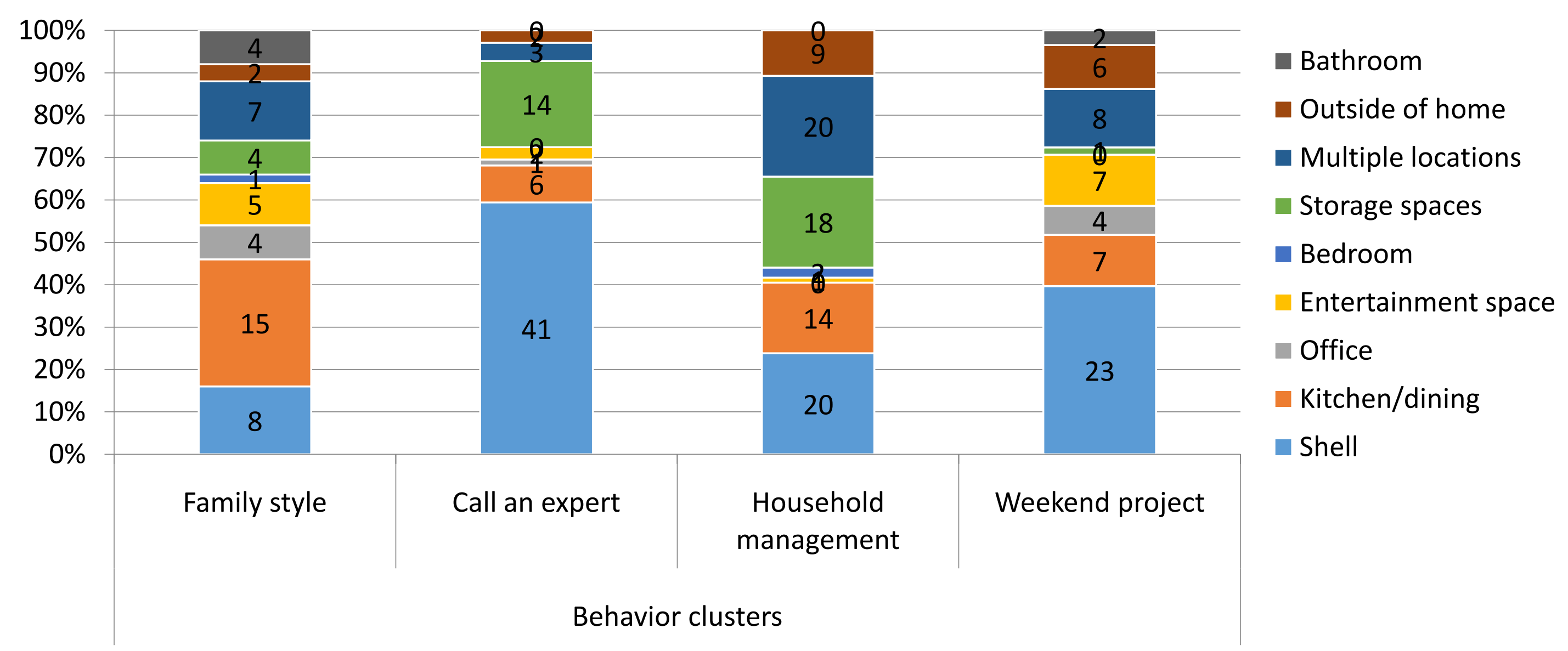




\section{Figure 4}

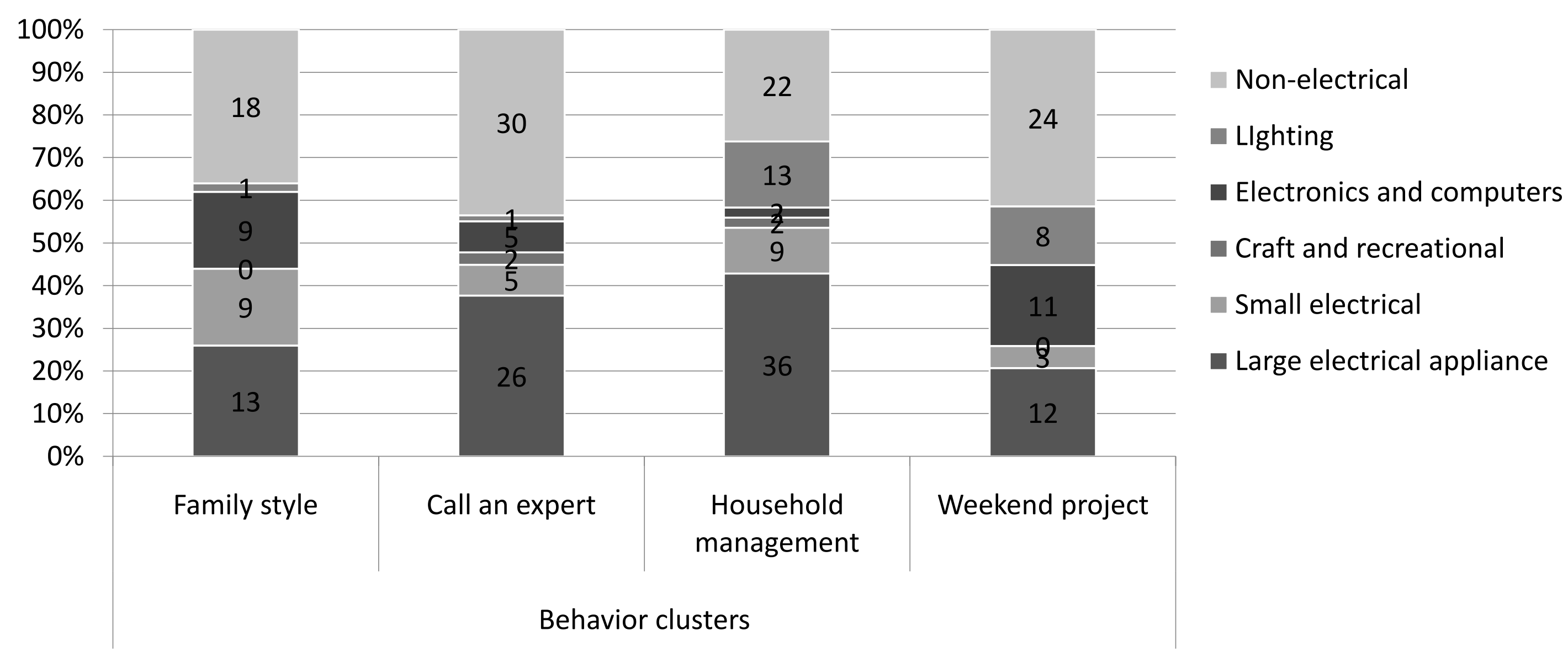




\section{Figure 4 (online)}

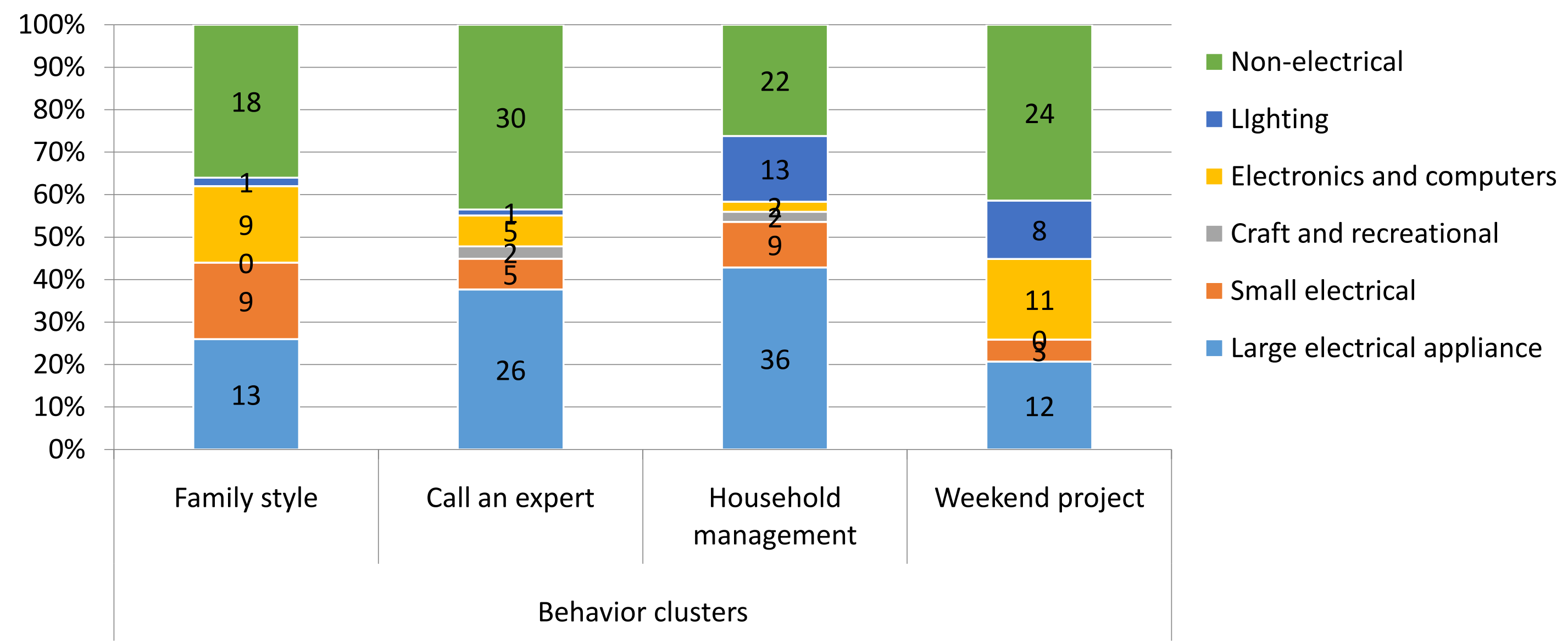

